\title{
23 PREVALENCE OF OSTEOPOROSIS AMONGST A LARGE COELIAC COHORT SUPPORTS EARLY BONE MINERAL DENSITY ASSESSMENT FOR ALL PATIENTS
}

J Collum, M Corrigan, A Smith, K Martin Department of Gastroenterology, University Hospital Aintree, Liverpool, UK

10.1136/gutjnl-2013-305143.23

Introduction Coeliac disease is associated with osteoporosis and osteoporosis is a significant public health problem (1). However, debate exists concerning the routine use of bone mineral density (BMD) assessment at time of coeliac diagnosis. Aims/Background To determine the prevalence of osteoporosis in patients with coeliac disease, as defined by BMD assessment, and the impact of factors such as gender, age \& disease duration.

Method We retrospectively analysed dietitian held data sets, which are kept for all patients with coeliac disease.

Results The data sets for 232 patients were available for analysis. The index BMD assessment was recorded. The prevalence of osteoporosis was $23 \%$. Overall, males were found to have lower average BMD than females. BMD decreased with advancing age. This finding was statistically significant $(\mathrm{p}<0.01)$. Greater duration of disease was associated with low BMD, but this did not reach statistical significance. $(p=0.42)$

Conclusion Due to a period of undiagnosed coeliac disease with latent calcium malabsorption, reduced BMD is likely to be present at time of diagnosis. Whilst osteoporosis is often asymptomatic until fracture, when fractures do occur they carry a significant morbidity and mortality. Screening allows identification of reduced BMD prior to fracture and subsequent management strategies can be instigated to improve this. The use of BMD assessment at diagnosis is gaining widespread support, but has not been formalised in UK guidelines (4). This screening strategy is likely to be cost effective, due to the widespread availability of BMD assessment and the markedly decreased cost of bisphosphonate therapy (6). 